\title{
A Participatory Assessment of the Impact of Flooding in Some Communities in Lokoja, Kogi State, Nigeria
}

\author{
Felix Ndukson Buba*, Samam Obaguo, Okibe Ogah, Felicia Oluwatoyin Ajayi \\ African Regional Centre for Space Science and Technology Education in English (ARCSSTE-E), Obafemi Awolowo University \\ Campus, Ile-Ife, Nigeria \\ Email: ^bubadillo@gmail.com
}

How to cite this paper: Buba, F. N., Obaguo, S., Ogah, O., \& Ajayi, F. O. (2021). A Participatory Assessment of the Impact of Flooding in Some Communities in Lokoja, Kogi State, Nigeria. American Journal of Climate Change, 10, 12-31.

https://doi.org/10.4236/ajcc.2021.101002

Received: August 6, 2020

Accepted: March 14, 2021

Published: March 17, 2021

Copyright $\odot 2021$ by author(s) and Scientific Research Publishing Inc. This work is licensed under the Creative Commons Attribution International License (CC BY 4.0).

http://creativecommons.org/licenses/by/4.0/

\begin{abstract}
The frequency and consequences of extreme flood events have increased in recent times, having huge impact on the socio-economic well-being of nations with the most significant impact being felt at the community level. Flooding is the most common environmental hazard in Nigeria, particularly Lokoja, with the frequency, intensity, and extent likely to increase due to the effects of global warming leading to climate change such as sea level rise, more intensive precipitation levels, and higher river discharges. While destructive impacts of flood events continue to increase, flood managers in Nigeria have continued to implement a top-down approach towards mitigating these impacts, without involving affected communities in planning and implementation of mitigation strategies. This study therefore employed a participatory approach to determine the causes and impact of flooding in the study area. Participatory research tools such as key informant interviews, focus group discussions, and questionnaire surveys using the purposive sampling method were deployed to elicit data on the perception of the communities about the causes and impact of flood events. Descriptive statistical analysis was performed to elucidate the major causes and areas of impact while qualitative analysis was carried out to corroborate the results and to make for a robust outcome. The Chi Square Test analysis was performed to empirically establish a relationship between the impacts and flooding. Results show that major causes of flooding are the release of water from dams (83\% in Adankolo, $97 \%$ in Gadumo, and $100 \%$ in Ganaja), overflow of rivers, and heavy rainfall while flooding affects economic concerns, property and basic amenities. The Chi Square Test analysis determined empirically that a relationship exists between several areas of impact and flood occurrence. The research concludes that participatory flood research approach can provide flood man-
\end{abstract}


agers and decision makers a bottom-up approach for effective and robust flood mitigation strategies.

\section{Keywords}

Flood Impact, Participatory Approach, Chi Square Test, Top-Down, Bottom-Up, Mitigation

\section{Introduction}

Over the years the world has witnessed several notable disasters which have caused large fatalities, devastating economic losses, and incredible environmental damages, with the most significant impact of natural disasters being felt at the community level. Floods are among the most devastating natural disasters in the world, claiming more lives and causing more damage to properties than any other natural phenomena, as well as being the most widespread (Kundu \& Kundu, 2011; Rabalao, 2010). Statistically, every year approximately 100 million people are affected by episodes of flooding globally (Sayama et al., 2010).

Developing countries especially in the African continent are vulnerable to flood disasters due to the weakness of state infrastructure and absence or lack of implementation of appropriate policies guiding disaster reduction and prevention. Nigeria is one of the most disaster-prone countries in Africa, and floods are the most common and recurring natural disaster, with the frequency, severity, and spread of these floods increasing (FGN, 2013). The most devastating floods in the history of the country occurred between July and October 2012, affecting 25 of the 36 states. The impact was very high and unprecedented in terms of human, material, and production loss: 363 people killed, 5851 injured, 3,891,304 affected, and 387,153 displaced (FGN, 2013). Flooding is a frequent phenomenon in major urban centres such as Lagos, Port Harcourt, Kano, Kaduna, etc.

Floods can be caused by anthropogenic activities which are human intervention in the natural processes which may include increase in settlement areas; population growth in low-lying plains prone to flooding leading to alterations in the natural drainage and river basin system; deforestation and climate change; and urbanization (Nharo, 2016; Adefisan et al., 2015; Nkwunonwo et al., 2015; Komolafe et al., 2015; Iyi \& Ugwuanyi, 2014; FGN, 2013; Ojigi et al., 2013; Santato et al., 2013; WMO, 2008). Attempts by man to harness available water resources have resulted in the construction of dams and other water control structures. The failures of these structures have resulted in floods (Komolafe et al., 2015; Rabalao, 2010).

Rabalao (2010) investigated the social, psychological and economic impact of flooding in Ga-Motla and Ga-Moeka communities of Moretele district in northwest province, South Africa, using participatory approach through questionnaire administration, and concluded that the changing environment due to urbanization, sprawl, and increase in population density exacerbate the impacts 
of flooding. Hu et al. (2019) investigated the impact of flooding on the Chinese economy from the perspective of the manufacturing sector and found that large flood events on average reduce firm outputs (measured by labour productivity) by about $28.3 \%$ per year. Using an input-output analysis, the study estimated the potential macro-economic impact to be $12.3 \%$ annual loss in total output, which amounts to 15,416 RMB billion, which indicates that the scale of economic impacts from flooding is much larger than microanalyses of direct damage indicates.

Tawari-Fufeyin et al. (2015) conducted a study to evaluate the effects of the Nigerian 2012 flood waters in selected towns of Bayelsa and Delta States in terms of some physical and chemical parameters. The study concluded that although the communities were adversely affected by the floods in terms of their livelihoods with a likelihood of some effects on the potable water sources of the communities, the study did not, however, reveal any significant or drastic effect on the water sources as most of the parameters measured were within allowable limits set by the World Health Organization (WHO). Umaru and Hafiz (2019) conducted another study to examine the perceived effects of flooding on lives and properties of the residents of Lokoja. Although results showed that flooding caused damage to household properties, vehicles, building collapse, farmlands, etc., the study did not seek to empirically establish a relationship between flood events and the identified impacts.

The need to involve the public in the process of decision-making for sustainable development is increasingly being recognized. Participation is hence a central issue within the field of development cooperation, participatory development being defined as a partnership which is built upon the basis of dialogue among the various actors, during which the agenda is jointly set, and local views and indigenous knowledge are deliberately sought and respected (Kienberger \& Steinbruch, 2005). Participatory development involves people who are affected by developmental processes as planners and implementers. It is a way of overcoming the shortcomings of top-down development and the limitations of expert research and planning (Development Studies Network, 2013).

The aim of participatory approach is to facilitate the identification of problems peculiar to an environment by the indigenous citizens and not outsiders who assume what their problems are. The best practice guidance on flood prevention, protection, and mitigation from the European Union Water Directives stipulates that public participation in decision-making concerning flood prevention and protection is needed, both to improve the quality and the implementation of the decisions and to give the public the opportunity to express its concerns and to enable authorities take due account of such concerns (Demeritt \& Nobert, 2014). The common practice of eliciting comments only after most of the work of reaching a decision has been done is cause for resentment, while many decisions can be better informed and their information base can be more credible if the interested and affected parties are appropriately and effectively involved (Cinderby \& Forrester, 2016). 
So far, state and government agencies have played a dominant role in shaping policy responses and decision-making for flood management (known as the top-down approach) in Nigeria, with inadequate space for non-state actors and local communities (Olorunfemi, 2011). This has resulted in significant shortcomings in the formulation of flood management strategies. This situation informed the participatory approach adopted in this research.

Flood disasters in Kogi State, particularly Lokoja and its environs have been a recurring phenomenon. In 2010 and 2012 several communities in Lokoja, Ibaji, and Kogi Local Government Areas (LGAs) were devastated by flooding. Three hundred and forty-four (344) communities of the State were affected by the 2012 floods with many farmlands submerged (Okpala-Okaka et al., 2013). Aside from the loss of lives and properties, floods prevent the optimal exploitation of the land and proper management and control of water resources (Ojigi et al., 2013).

This research employed a participatory approach to assess the impact of flood events on three communities that are inundated almost on an annual basis in Lokoja. The study set out to elicit the causes and impact of flooding, and to determine or establish an empirical relationship between flood events and the identified impacts. By adopting participatory approach, the researchers are convinced that the most vulnerable groups and the threats they face can be better identified because local knowledge can improve the way in which internal and external actors understand flood risk and take decisions about flood management.

\section{Materials and Methods}

\subsection{Study Area}

Nigeria has two major drainage systems flowing through it: the Rivers Niger and Benue that divide the country into three unequal geographical regions with a confluence in the Lokoja area of Kogi State, making Kogi State and Lokoja in particular one of the areas frequently affected by floods (Oluwaseun et al., 2013). The study area is located in Lokoja, at latitude $7^{\circ} 45^{\prime} 0^{\prime \prime} \mathrm{N}$ to $7^{\circ} 53^{\prime} 30^{\prime \prime} \mathrm{N}$ and longitude $6^{\circ} 43^{\prime} 0$ "E to $6^{\circ} 51^{\prime} 30$ "E (see Figure 1), with a total land area of $29,833 \mathrm{~km}^{2}$ (Adefisan \& Egiku, 2018). Communities located around the channels and at the confluence of these rivers bear the full brunt of the impacts of flood events, with three of these communities, Gadumo, Adankolo, and Ganaja, among the most affected.

The climate of the study area is characterized by wet and dry seasons: the dry season lasts from November to February while the wet season lasts from March to October. The annual rainfall is between $1016 \mathrm{~mm}$ and $1524 \mathrm{~mm}$; the city is generally hot throughout the year with an annual temperature of $27^{\circ} \mathrm{C}$ (Alabi, 2009). Economically, the strategic central location of the city and its location at the confluence region of the two great rivers Niger and Benue attracted many ethnic groups and individuals. Economic activities such as agriculture, spinning, weaving, blacksmithing, pottery, dyeing, fishing, etc are carried out by the 


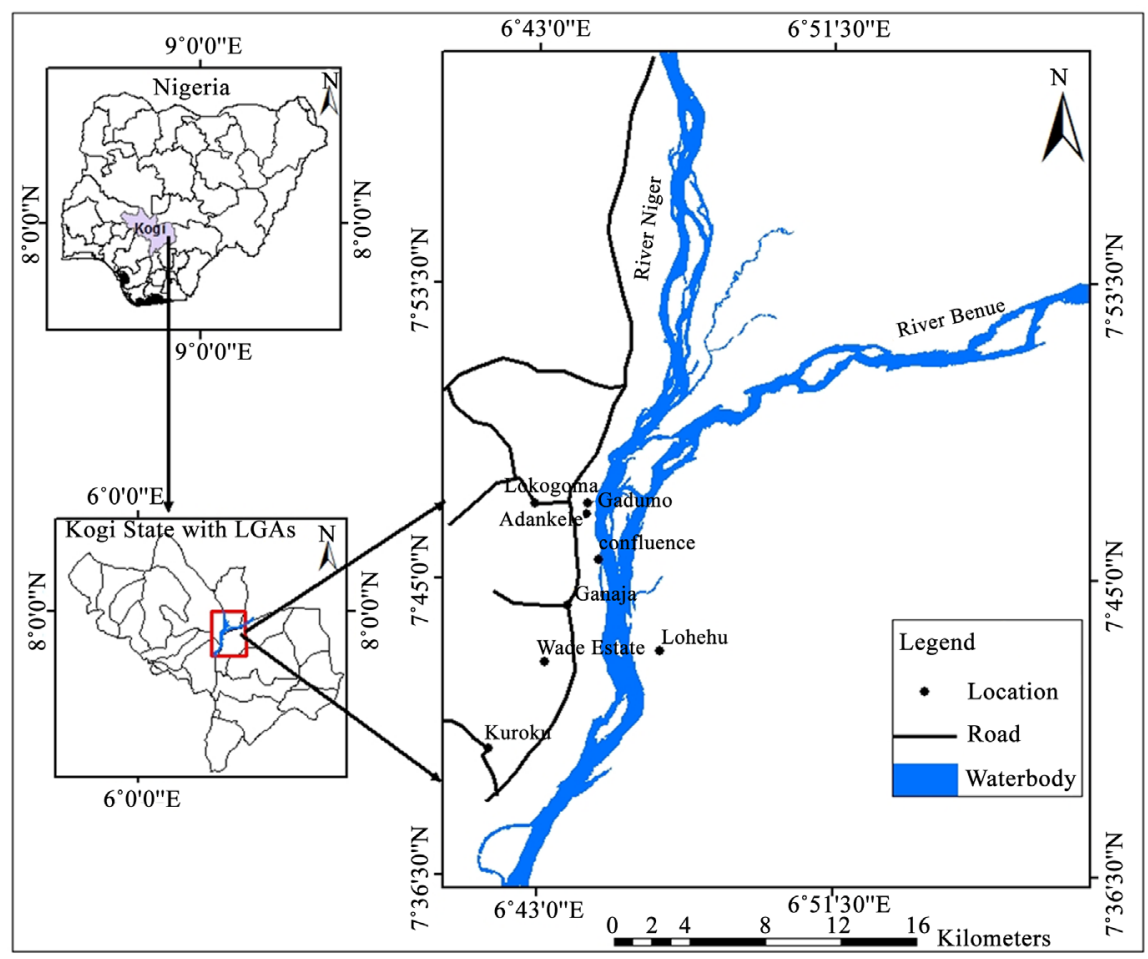

Figure 1. Map of the study area.

various ethnic groups in Lokoja (Audu, 2009), with agriculture being the main occupation of the people.

\subsection{Data Requirements}

The research collected data from a sample of an identified population, employing a combination of questionnaire survey and interview survey. It employed purposive sampling technique for the administration of questionnaires and the snowball or chain-referral sampling technique was employed for interviews (key informants and focus group discussions). The chain-referral method is a technique of sampling based on purposive sampling, normally used to select respondents based on their expertise, experiences and job responsibilities (Maferetlhane, 2012). The chain-referral involves an iterative process to identify relevant personalities through interviews with state and local officials, traditional rulers, and other relevant stakeholders referred to the researcher (Lo et al., 2012, cited in Buba, 2016). This maximizes the efficiency of stakeholder identification that leads to a representation of a wide range of situated knowledge and expertise including certified experts and key player organizations, and uncertified experts from local communities and Non-Governmental Organizations (Maskrey et al., 2016).

Community support and approval for the study were obtained through meetings with traditional leadership, political structures (ward councillors and development committees) and other stakeholders. Primary data collection was achieved through participatory approaches, that is, the application of tools for 
eliciting the local knowledge and perceptions such as interviews and questionnaire administration surveys. Some of the stakeholders involved in the study include community representatives from affected sectors such as trade and agriculture, government officials, elders, village heads and chiefs and other community leaders, and victims of flood events.

Fieldwork was undertaken for the purposes of participatory data collection. The initial activities were comprised of visits to the local government and interactions with some of the local people. Based on these initial activities, a selection was made of the communities that were always inundated and worst hit by flooding. In this regard, three (3) communities were identified which included Ganaja, Gadumo, and Adankolo. These were the communities that were studied in detail. During this step it was important to clearly discuss the purpose of the work, being purely academic, to avoid creating different expectations from the people. This initial approach was necessary in order to create empathy and rapport with the local people which is important when carrying out community-based research.

The knowledge captured included flood events experienced in terms of magnitude, type, and frequency; causes of floods; and impacts in terms of physical, economic, and social effects. The participatory tools employed include:

1) Key informant interview (KII): semi-structured interviews guided by a set of questions but conducted in a semi-open format to allow the interviewee to talk freely about the issues. The researchers conducted a total of three (3) key informant interviews, one key informant selected for each of the three villages, the selection done through the chain referral sampling technique.

2) Focus group discussions (FGD): conducted mainly with community members affected by flooding. A total of three focus group discussions were held, one in each of the three villages. Participants were informed and mobilized beforehand through the village heads and community leaders. Participants were encouraged to freely contribute their views on all issues concerning the research topic, although the discussions were guided by a set of questions.

3) Questionnaire Administration Survey: a detailed survey was conducted, making use of a purposive sampling method for questionnaire administration. A total of one hundred and seventy number of questionnaires were administered while one hundred and sixty-nine were retrieved: sixty-seven for Ganaja village, fifty-three for Gadumo village, and 49 for Adankolo village.

Data from focus group discussions and key informant interviews were audio recorded and stored in a password-protected system to ensure confidentiality and access to the researchers only. The audio recordings were transcribed and the transcripts subjected to further analysis.

\subsection{Analyses}

Data from the questionnaire survey were analysed using the SPSS package. Two main analyses were conducted. Descriptive statistical analysis was done to determine the frequency and percentages of respondents as regards the causes of 
flooding in the study area and to also determine the major areas of livelihood of the people impacted. The major areas determined to be impacted by flooding were subjected to further analysis using the Chi Square inferential statistical test to empirically determine if there is any association between the areas impacted and flooding. The Chi square test is a statistical test which measures the association between two categorical variables (Ugoni \& Walker, 1995), and is calculated under the assumption of no association, with the degree of freedom given as one (1) at $5 \%$ level of significance ( $95 \%$ confidence level). The rule for making a decision is that if the $p$-value $<0.05$, we conclude that an association exists while if the $p$-value $>0.05$, we conclude that no association exists, where the $p$-value is the probability of observing a sample statistic as extreme as the test statistic.

Data from focus group discussions and key informant interviews were qualitatively analysed, adopting a thematic analytical approach to derive recurring categories and themes. The transcripts were used to develop a codebook using a hybrid of inductive approach. The quotations from participants were pooled together to understand patterns across the data.

\section{Results and Discussion}

\subsection{Results}

Data generated from the questionnaire administration during the fieldwork were analysed using the SPSS package to determine the causes of flood events and to assess the impact of flood events on the communities in the study area. Table 1 an Table 2 detail the causes of floods while Tables 3-7 detail the areas most impacted by the flood events.

Table 1. Major causes of flood events in the study area.

\begin{tabular}{ccccccc}
\hline & \multicolumn{2}{c}{ Adankolo } & \multicolumn{2}{c}{ Gadumo } & \multicolumn{2}{c}{ Ganaja } \\
\cline { 2 - 6 } & Frequency & Percent (\%) & Frequency & Percent (\%) & Frequency & Percent (\%) \\
\hline Heavy rainfall & 15 & 24.2 & 34 & 44.7 & 33 & 42.9 \\
Overflow of rivers & 47 & 75.8 & 41 & 54.0 & 44 & 57.1 \\
No response & 0 & 0 & 1 & 1.3 & 0 & 0 \\
Total & 62 & 100 & 76 & 100 & 77 & 100 \\
\hline
\end{tabular}

Table 2. Other causes of flooding.

\begin{tabular}{ccccccc}
\hline & \multicolumn{2}{c}{ Adankolo } & \multicolumn{2}{c}{ Gadumo } & \multicolumn{2}{c}{ Ganaja } \\
\cline { 2 - 7 } & Frequency & Percent (\%) & Frequency & Percent (\%) & Frequency & Percent (\%) \\
\hline $\begin{array}{c}\text { Opening of dam } \\
\text { Erosion }\end{array}$ & 15 & 83.3 & 36 & 97.3 & 27 & 100 \\
$\begin{array}{c}\text { Lack of drainage } \\
\text { system }\end{array}$ & 2 & 11.1 & 0 & 0 & 0 & 0 \\
$\begin{array}{c}\text { Cutting down } \\
\text { of trees }\end{array}$ & 0 & 0 & 1 & 2.7 & 0 & 0 \\
Total & 18 & 100 & 37 & 100 & 27 & 100 \\
\hline
\end{tabular}


Table 3. Major economic concerns affected by flooding in the study area.

\begin{tabular}{ccccccc}
\hline & \multicolumn{2}{c}{ Adankolo } & \multicolumn{2}{c}{ Gadumo } & \multicolumn{2}{c}{ Ganaja } \\
\cline { 2 - 7 } & Frequency & Percent (\%) & Frequency & Percent (\%) & Frequency & Percent (\%) \\
\hline Farmlands & 47 & 58.0 & 52 & 41.6 & 60 & 42.5 \\
Markets & 12 & 14.8 & 31 & 24.8 & 42 & 29.8 \\
$\begin{array}{c}\text { Transportation } \\
\text { system }\end{array}$ & 21 & 25.9 & 41 & 32.8 & 33 & 23.4 \\
$\begin{array}{c}\text { Electricity supply } \\
\text { Total }\end{array}$ & 1 & 1.3 & 1 & 0.8 & 6 & 4.3 \\
\hline
\end{tabular}

Table 4. Other economic losses due to flooding.

\begin{tabular}{ccccccc}
\hline & \multicolumn{2}{c}{ Adankolo } & \multicolumn{2}{c}{ Gadumo } & \multicolumn{2}{c}{ Ganaja } \\
\cline { 2 - 7 } & Frequency & Percent (\%) & Frequency & Percent (\%) & Frequency & Percent (\%) \\
\hline $\begin{array}{c}\text { Affected animals } \\
\text { Collapse of }\end{array}$ & 2 & 25 & 4 & 40 & 0 & 0 \\
$\begin{array}{c}\text { houses and shops } \\
\text { Documents } \\
\text { destroyed }\end{array}$ & 6 & 75 & 5 & 50 & 4 & 80 \\
$\begin{array}{c}\text { Reduction of } \\
\text { house rent }\end{array}$ & 0 & 0 & 1 & 10 & 0 & 0 \\
$\quad$ Total & 8 & 100 & 10 & 100 & 5 & 100 \\
\hline
\end{tabular}

Table 5. Basic amenities affected by flooding in the study area.

\begin{tabular}{ccccccc}
\hline & \multicolumn{2}{c}{ Adankolo } & \multicolumn{2}{c}{ Gadumo } & \multicolumn{2}{c}{ Ganaja } \\
\cline { 2 - 7 } & Frequency & Percent (\%) & Frequency & Percent (\%) & Frequency & Percent (\%) \\
\hline Roads & 41 & 27.9 & 47 & 31.6 & 43 & 27 \\
Water supply & 18 & 12.2 & 40 & 26.8 & 36 & 22.6 \\
Health facilities & 5 & 3.4 & 2 & 1.3 & 7 & 4.5 \\
Schools & 34 & 23.1 & 6 & 4.0 & 9 & 5.6 \\
Houses & 48 & 32.7 & 53 & 35.6 & 64 & 40.3 \\
Documents & 1 & 0.7 & 0 & 0 & 0 & 0 \\
Student activities & 0 & 0 & 1 & 0.7 & 0 & 0 \\
Total & 147 & 100 & 149 & 100 & 159 & 100 \\
\hline
\end{tabular}

Table 6. Outbreak of major diseases due to flooding in the study area.

\begin{tabular}{ccccccc}
\hline & \multicolumn{2}{c}{ Adankolo } & \multicolumn{2}{c}{ Gadumo } & \multicolumn{2}{c}{ Ganaja } \\
\cline { 2 - 6 } & Frequency & Percent (\%) & Frequency & Percent (\%) & Frequency & Percent (\%) \\
\hline Cholera & 28 & 32.6 & 42 & 32.3 & 50 & 34.0 \\
Typhoid fever & 27 & 31.4 & 38 & 29.2 & 44 & 29.9 \\
Malaria & 31 & 36 & 50 & 38.5 & 46 & 31.3 \\
Hepatitis & 0 & 0 & 0 & 0 & 7 & 4.8 \\
Total & 86 & 100 & 130 & 100 & 147 & 100 \\
\hline
\end{tabular}


Table 7. Other diseases due to flooding.

\begin{tabular}{ccccccc}
\hline & \multicolumn{2}{c}{ Adankolo } & \multicolumn{2}{c}{ Gadumo } & \multicolumn{2}{c}{ Ganaja } \\
\cline { 2 - 7 } & Frequency & Percent (\%) & Frequency & Percent (\%) & Frequency & Percent (\%) \\
\hline Snake bite & 1 & 25 & 1 & 33.4 & 0 & 0 \\
Leg cut & 2 & 50 & 0 & & 0 & 0 \\
Skin problem & 1 & 25 & 0 & & & 0 \\
Guinea worm & 0 & 0 & 1 & 33.3 & 0 & 0 \\
Cold & 0 & 0 & 1 & 33.3 & 0 & 0 \\
Total & 4 & 100 & 3 & 100 & 0 & 0 \\
\hline
\end{tabular}

The data were also analysed using the Chi square test to determine the association between flooding and various impacts assessed. Some of the impacts of flooding on the communities from community-generated data and assessed by the study include the effects of flooding on markets, transportation system, farmlands, water supply, health facilities, electricity supply, schools, houses, and on health concerns such as cholera, typhoid fever, malaria, and hepatitis.

\section{Assumption 1:}

The transportation system is NOT affected by flood occurrence.

\begin{tabular}{cccc}
\hline Alternatives & Observed & Expected & Residual \\
\hline Yes & 95 & 115.1 & -20.1 \\
No & 74 & 53.9 & 20.1 \\
Degree of freedom & & $\mathrm{df}=1$ & \\
Chi-Square & $\mathrm{X}^{2}=10.962^{\mathrm{a}}$ & \\
$p$-value & $p=0.001$ & \\
\hline
\end{tabular}

\section{Determination of critical value}

Degree of freedom is given by $\mathrm{df}=1$ at $5 \%$ level of significance.

$\mathrm{X}^{2}=10.962^{\mathrm{a}}$

$p=0.001$

Decision rule: reject assumption if $p$-value $<0.05$ and accept if $p$-value $>0.05$.

Since $p$-value (0.001) is less than 0.05 , the assumption of no association was rejected. This implies that the transportation system is affected by flood occurrence.

\section{Assumption 2:}

Farmlands are NOT affected by flood occurrence.

\begin{tabular}{cccc}
\hline Alternatives & Observed & Expected & Residual \\
\hline Yes & 159 & 147.9 & 11.1 \\
No & 10 & 21.1 & -11.1 \\
Degree of freedom & & $\mathrm{df}=1$ & \\
Chi-Square & & $\mathrm{X}^{2}=6.696^{\mathrm{a}}$ & \\
$p$-value & & $p=0.010$ & \\
\hline
\end{tabular}




\section{Determination of critical value}

Degree of freedom is given by $\mathrm{df}=1$ at $5 \%$ level of significance.

$\mathrm{X}^{2}=6.696^{\mathrm{a}}$

$p=0.010$

Decision rule: reject assumption if $p$-value $<0.05$ and accept if $p$-value $>0.05$.

Since $p$-value $(0.010)$ is less than 0.05 , the assumption of no association was rejected. This implies that farmlands are affected by flood occurrence.

\section{Assumption 3:}

Markets are NOT affected by flood occurrence.

\begin{tabular}{cccc}
\hline Alternatives & Observed & Expected & Residual \\
\hline Yes & 131 & 112.7 & 18.3 \\
No & 38 & 56.3 & -18.3 \\
Degree of freedom & & $\mathrm{df}=1$ & \\
Chi-Square & & $\mathrm{X}^{2}=8.950^{\mathrm{a}}$ & \\
$p$-value & & $p=0.003$ & \\
\hline
\end{tabular}

\section{Determination of critical value}

Degree of freedom is given by $\mathrm{df}=1$ at $5 \%$ level of significance.

$\mathrm{X}^{2}=8.950^{\mathrm{a}}$

$p=0.003$

Decision rule: reject assumption of no association if $p$-value $<0.05$ and accept if $p$-value $>0.05$.

Since $p$-value $(0.003)$ is less than 0.05 , the assumption of no association was rejected. This implies that markets are also affected by flood occurrence.

\section{Assumption 4:}

Water supply is NOT affected by flood occurrence.

\begin{tabular}{cccc}
\hline Alternatives & Observed & Expected & Residual \\
\hline Yes & 94 & 112.7 & -18.7 \\
No & 75 & 56.3 & 18.7 \\
Degree of freedom & & $\mathrm{df}=1$ & \\
Chi-Square & & $\mathrm{X}^{2}=9.278^{\mathrm{a}}$ & \\
$p$-value & $p=0.002$ & \\
\hline
\end{tabular}

\section{Determination of critical value}

Degree of freedom is given by $\mathrm{df}=1$ at $5 \%$ level of significance.

$\mathrm{X}^{2}=9.278^{\mathrm{a}}$

$p=0.002$

Decision rule: reject assumption of no association if $p$-value $<0.05$ and accept if $p$-value $>0.05$.

Since $p$-value (0.002) is less than 0.05 , the assumption of no association was 
rejected. This implies that the water supply is also affected by flood occurrence.

\section{Assumption 5:}

Health facilities are NOT affected by flood occurrence.

\begin{tabular}{cccc}
\hline Alternatives & Observed & Expected & Residual \\
\hline Yes & 14 & 18.8 & -4.8 \\
No & 155 & 150.2 & 4.8 \\
Degree of freedom & & $\mathrm{df}=1$ & \\
Chi-Square & $\mathrm{X}^{2}=1.368^{\mathrm{a}}$ & \\
$p$-value & $p=0.242$ & \\
\hline
\end{tabular}

\section{Determination of critical value}

Degree of freedom is given by $\mathrm{df}=1$ at $5 \%$ level of significance.

$\mathrm{X}^{2}=1.368^{\mathrm{a}}$

$p=0.242$

Decision rule: reject assumption of no association if $p$-value $<0.05$ and accept if $p$-value $>0.05$.

Since $p$-value $(0.242)$ is greater than 0.05 , the assumption of no association was accepted. This implies that the health facilities in the study area are not affected by flood occurrence.

\section{Assumption 6:}

Electricity supply is NOT affected by flood occurrence.

\begin{tabular}{cccc}
\hline Alternatives & Observed & Expected & Residual \\
\hline Yes & 8 & 9.4 & -1.4 \\
No & 161 & 159.6 & 1.4 \\
Degree of freedom & & $\mathrm{df}=1$ & \\
Chi-Square & & $\mathrm{X}^{2}=0.218^{\mathrm{a}}$ & \\
$p$-Value & $p=0.641$ & \\
\hline
\end{tabular}

\section{Determination of critical value}

Degree of freedom is given by $\mathrm{df}=1$ at $5 \%$ level of significance.

$\mathrm{X}^{2}=1.368^{\mathrm{a}}$

$p=0.641$

Decision rule: reject assumption of no association if $p$-value $<0.05$ and accept if $p$-value $>0.05$.

Since $p$-value $(0.641)$ is greater than 0.05 , the assumption of no association was accepted. This implies that the electricity facilities in the study area are not affected by flood occurrence.

\section{Assumption 7:}

School facilities are NOT affected by flood occurrence. 


\begin{tabular}{cccc}
\hline Alternatives & Observed & Expected & Residual \\
\hline Yes & 49 & 42.3 & 6.8 \\
No & 120 & 126.8 & -6.8 \\
Degree of freedom & & $\mathrm{df}=1$ & \\
Chi-Square & & $\mathrm{X}^{2}=1.438^{\mathrm{a}}$ & \\
$p$-Value & & $p=0.230$ & \\
\hline
\end{tabular}

\section{Determination of critical value}

Degree of freedom is given by $\mathrm{df}=1$ at $5 \%$ level of significance.

$\mathrm{X}^{2}=1.438^{\mathrm{a}}$

$p=0.230$

Decision rule: reject assumption of no association if $p$-value $<0.05$ and accept if $p$-value $>0.05$.

Since $p$-value $(0.230)$ is greater than 0.05 , the assumption of no association was accepted. This implies that school facilities in the study area are not affected by flood occurrence.

\section{Assumption 8:}

Houses are NOT affected by flood occurrence.

\begin{tabular}{cccc}
\hline Alternatives & Observed & Expected & Residual \\
\hline Yes & 165 & 153.6 & 11.4 \\
No & 4 & 15.4 & -11.4 \\
Degree of freedom & & $\mathrm{df}=1$ & \\
Chi-Square & & $\mathrm{X}^{2}=9.246^{\mathrm{a}}$ & \\
$p$-Value & & $p=0.002$ & \\
\end{tabular}

\section{Determination of critical value}

Degree of freedom is given by $\mathrm{df}=1$ at $5 \%$ level of significance.

$\mathrm{X}^{2}=9.246^{\mathrm{a}}$

$p=0.002$

Decision rule: reject assumption of no association if $p$-value $<0.05$ and accept if $p$-value $>0.05$.

Since $p$-value (0.002) is less than 0.05 , the assumption of no association was rejected. This implies that houses in the study area are affected by flood occurrence.

\section{Assumption 9:}

There is NO cholera outbreak after the flood occurrence.

\begin{tabular}{cccc}
\hline Alternatives & Observed & Expected & Residual \\
\hline Yes & 120 & 135.2 & -15.2 \\
No & 49 & 33.8 & 15.2 \\
Degree of freedom & & $\mathrm{df}=1$ & \\
Chi-Square & & $\mathrm{X}^{2}=8.544^{\mathrm{a}}$ & \\
$p$-value & & $p=0.003$ & \\
\hline
\end{tabular}




\section{Determination of critical value}

Degree of freedom is given by $\mathrm{df}=1$ at $5 \%$ level of significance.

$\mathrm{X}^{2}=8.544^{\mathrm{a}}$

$p=0.003$

Decision rule: reject assumption of no association if $p$-value $<0.05$ and accept if $p$-value $>0.05$.

Since $p$-value $(0.003)$ is less than 0.05 , the assumption of no association was rejected. This implies that cholera outbreaks affect people in the communities after a flood occurrence.

Assumption 10:

Typhoid fever DOES NOT affect people after a flood occurrence.

\begin{tabular}{cccc}
\hline Alternatives & Observed & Expected & Residual \\
\hline Yes & 109 & 120.7 & -11.7 \\
No & 60 & 48.3 & 11.7 \\
Degree of freedom & & $\mathrm{df}=1$ & \\
Chi-Square & & $\mathrm{X}^{2}=3.979^{\mathrm{a}}$ & \\
$p$-Value & & $p=0.046$ & \\
\hline
\end{tabular}

\section{Determination of critical value}

Degree of freedom is given by $\mathrm{df}=1$ at $5 \%$ level of significance.

$\mathrm{X}^{2}=3.979^{\mathrm{a}}$

$p=0.046$

Decision rule: reject assumption of no association if $p$-value $<0.05$ and accept if $p$-value $>0.05$.

Since $p$-value $(0.046)$ is less than 0.05 , the assumption of no association was rejected. This implies that typhoid fever does affect people in the communities after a flood occurrence.

Assumption 11:

Malaria DOES NOT affect people after a flood occurrence.

\begin{tabular}{cccc}
\hline Alternatives & Observed & Expected & Residual \\
\hline Yes & 127 & 112.7 & 14.3 \\
No & 42 & 56.3 & -14.3 \\
Degree of freedom & & $\mathrm{df}=1$ & \\
Chi-Square & & $\mathrm{X}^{2}=5.470^{\mathrm{a}}$ & \\
$p$-Value & & $p=0.019$ &
\end{tabular}

\section{Determination of critical value}

Degree of freedom is given by $\mathrm{df}=1$ at $5 \%$ level of significance.

$\mathrm{X}^{2}=5.470^{\mathrm{a}}$

$p=0.019$ 
Decision rule: reject assumption of no association if $p$-value $<0.05$ and accept if $p$-value $>0.05$.

Since $p$-value (0.019) is less than 0.05 , the assumption of no association was rejected. This implies that malaria does affect people after a flood occurrence.

Assumption 12:

Hepatitis DOES NOT affect people after a flood occurrence.

\begin{tabular}{cccc}
\hline Alternatives & Observed & Expected & Residual \\
\hline Yes & 7 & 9.4 & -2.4 \\
No & 162 & 159.6 & 2.4 \\
Degree of freedom & & $\mathrm{df}=1$ & \\
Chi-Square & & $\mathrm{X}^{2}=0.644^{\mathrm{a}}$ & \\
$p$-Value & & $p=0.422$ & \\
\hline
\end{tabular}

\section{Determination of critical value}

Degree of freedom is given by $\mathrm{df}=1$ at $5 \%$ level of significance.

$\mathrm{X}^{2}=0.644^{\mathrm{a}}$

$p=0.422$

Decision rule: reject assumption of no association if $p$-value $<0.05$ and accept if $p$-value $>0.05$.

Since $p$-value $(0.422)$ is greater than 0.05 , the assumption of no association was accepted. This implies that cases of hepatitis do not arise in the study after a flood occurrence.

To further assess the impact of flooding in the study area, qualitative analysis of data from focus group discussion and key informant interview was undertaken. A cross section of participants expressed the following views:

\section{Destruction of property, relocation of residents, expansion of gutter}

$R$ : When flood comes, it will destroy so many houses and properties:

\section{KII_Adankolo.}

$R$ : The flood demolished/collapsed some of the houses that the foundations were not strong enough when building it. You can see that flood has collapsed some of the buildings. KII_Ganaja.

$R$ : Some have packed away from most of the affected houses permanently. For some since it occurs every year, they move out and after the flood they return after renovating the house: KII_Gadumo.

\section{Low/lack of business patronage, destruction of farm lands/animals}

$R$ : The patronage here is also low because nobody will want water to carry them away when they come here for business. If you are moving about you will be told that maybe the water has gone under with people: KII_Ganaja.

$P$... for example there are 10 rooms in this compound and I am occupying just a room so the challenge is that people will not agree to come back to rent this place after the flood because they are afraid of packing their properties out again when another flood occurs: FGD_Ganaja. 
$R$ : The challenge is that during the flood, there is no business activity going on here: KII_Gadnaja.

$R:$ If you have a fish pond here and if the water gets to a particular level, the fishes will be swept off, the flood will wipe away the house, and you can't use the lands for farming: KII_Ganaja.

$R:$ I had a house where I was rearing animals but when flood came, I had no place to pack them to ... And you are looking for buyer and there is none, so when there is no place to pack them to, that is how we lose our animals. This my neighbour Alhaji had goats, he lost them. Because when water is coming both animals and humans start running to save our lives: KII_Gadumo.

$R$ : The flood destroyed our crops e,g maize, rice, groundnut: KII_Gadumo.

$R$ : Look at our crops, I cultivated this farmland here but the flood came and destroyed it. Sometimes we will collect loan to farm and after farming, flood will move everything away. So where do you get money to pay back the loan, this will cause problem between us and the banks: KII_Adankolo.

Presence of dangerous animals, loss of life, dirty environment, paralysis of activities

$R$ : during flood, there is the presence of dangerous animals like snakes, scorpions: KII_Ganaja.

$P$ : when flood starts you will see different kinds of terrible snakes, even yesterday we still saw snakes coming out of the river. FGD_Gadumo.

$R$ : During the flood, a lot of people lost their lives: KII_Ganaja.

$P$. ... the farmland, everything even trees are dying; you can see that tree there dead not to talk about human lives: FGD_Gadumo.

$R$ : Then after the flood, the environment will be so dirty: KII_Ganaja.

$R$ : No activity goes on during the flood, people will have to run for their lives: KII_Ganaja.

Imposes hardship, invasion of disease and sickness, exploitation

P. flood imposes hardship on the community: FGD_Gadumo.

$P$. So now we don't have anything, not even food. We even beg people to give us a room to stay but they will not accept: FGD_Ganaja.

P. Even the water flowing here is so poisonous. You heard one of our elders here saying that his leg is paining him (disease): FGD_Gadumo.

$P$ : there is this infection around already; bacterial infection and all that, we have to fumigate: FGD_Gadumo.

$P$. it also came with a lot of sicknesses e.g diarrhoea, malaria, hepatitis: FGD_Ganaja.

P. when this flood comes, some people take it as an opportunity to make money from us; if you want to rent a room for just 1 or 2 months before you return to your house, somebody will tell you to pay \#30,000 for one-bedroom flat: FGD_Adankolo.

\subsection{Discussion}

Findings from the descriptive statistical analyses conducted on the data gener- 
ated from the questionnaire survey indicated that the major cause of flooding in the communities is the opening of Ladgo dam in Cameroun. In Adankolo community, $83 \%$ of respondents attribute flooding to the opening of the said dam while $97.3 \%$ and $100 \%$ of respondents in Gadumo and Ganaja communities respectively also attribute flooding in their communities to the opening of the dam. The next important cause of flooding in these communities is the overflow of rivers Niger, Benue, and Meme (Adankolo 75.8\%, Gadumo 54\%, and Ganaja $57.1 \%)$. The heavy rainfall experienced in these communities also causes flooding, to a lesser degree (Adankolo 24.2\%, Gadumo 44.7\%, and Ganaja 42.9\%). Other factors mentioned that exacerbate flooding but are not the cause include erosion and lack of drainage systems. These findings are consistent with a study conducted by Ojigi et al. (2013) on the geospatial mapping of the 2012 flood disaster in central parts of Nigeria. In the study, the researchers attributed the 2012 flooding to the release of waters from Ladgo dam in Cameroun into the River Benue floodplain.

Data from participatory approaches such as focus group discussions and key informant interviews were analysed qualitatively to also determine the causes of flooding. Qualitative analysis was done to corroborate the results from the questionnaire survey and to make the research more robust. After pooling the responses thematically, three main causes of flooding became apparent: release of water from dams, poor dam maintenance, and heavy rainfall. Results of the qualitative analysis of data from focus group discussions and key informant interviews relating to the causes of flooding were consistent and support results from questionnaire data analysis.

Findings from further analyses of the questionnaire survey data using the Chi square inferential statistical technique revealed an empirical association between the identified impacts with flooding in all the three communities. Impacts such as destruction of markets, transportation system, farmlands, water supply infrastructure, and houses (Figure 2) showed empirical association with flooding. Findings also revealed an empirical association between health challenges such

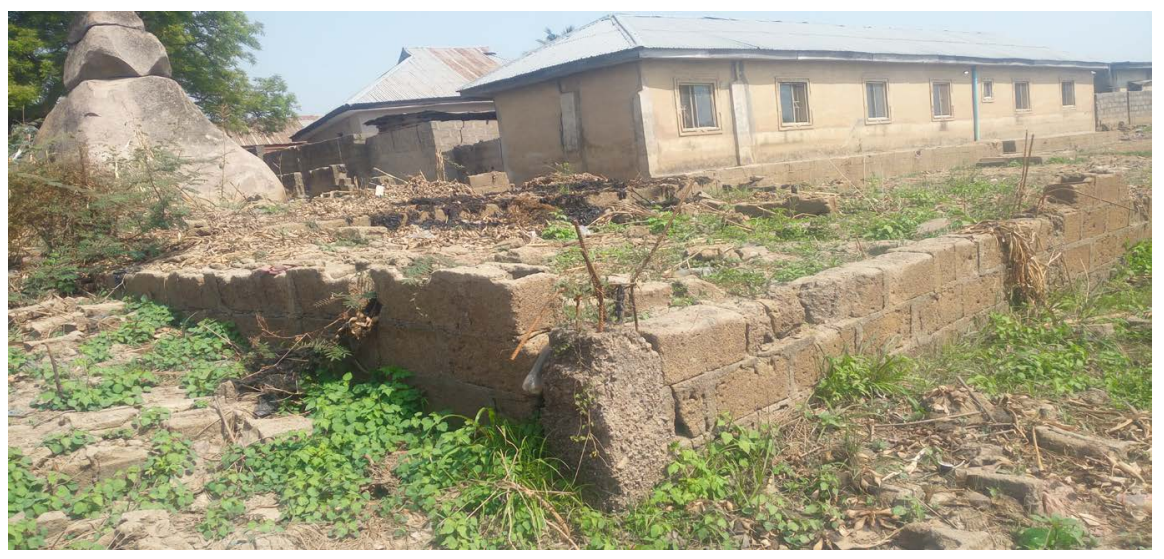

Figure 2. Property destroyed by a previous flood and a new one constructed on the same site at Adankolo (Source: fieldwork, 2019). 
as cholera, typhoid fever, and malaria. These findings are also consistent with a study carried out by Umaru and Hafiz (2019) on the perceived effects of flood on lives and properties of the residents of Lokoja. Their study showed that flooding caused damage to, among others, buildings, farmlands, and other infrastructure. An interesting aspect of the present study is that the Chi square statistical test showed no association between flooding and such infrastructure as water supply, health facilities, electricity supply and school facilities. This may be explained by the fact that such infrastructure are sited outside of the floodplain. Hepatitis as a health challenge did not show any association with flooding in the study area.

To further assess the impact of flooding in the study area, qualitative analysis of data from focus group discussion and key informant interview on areas of impact was undertaken. This was to also corroborate results from questionnaire survey and therefore make the research more robust. Pooling the responses of participants from these two interview types together, a thematic analysis revealed the following categories of impacts: destruction of property and houses, impromptu relocation of residents, low/lack of business patronage, destruction of farm lands/animals; presence of dangerous animals, loss of life, degrading the environment, paralysis of activities; hardship, diseases and sickness, and exploitation by unscrupulous landlords. These impacts as revealed from qualitative analysis of focus group discussion and key informant interviews were consistent and indeed corroborate the results from the questionnaire survey analysis.

This research has studied in some detail the impact of flooding in the communities that made up the study area. This information is very important in the context of contingency planning and emergency response, and therefore needed by flood managers and other relevant authorities. Knowing where the flood disaster has had the most impact will determine the direction of emergency response, relief and recovery and will also determine the thinking for contingency planning for future flood events. In developed countries, the information on the severity of flooding measured by the impact will be key in insurance claims. Equally important, the study has revealed that affected communities should be involved in a participatory and bottom-up manner in drawing up measures to mitigate the impacts of flooding, and indeed, in flood management strategies.

Flooding is a complex socio-environmental problem, and understanding its complexities requires consideration of multiple stakeholder perceptions and knowledge claims. This explains the multi-disciplinary nature of any research on flooding, employing a diverse knowledge base including the perception of the people directly affected by the disaster, because different types of knowledge about floods can come from both analysis by researchers and experiences of people in flood-affected areas. Investigating the impacts of flooding from the perspective of the affected communities will help policy and decision makers to employ a bottom-up approach to flood mitigation.

The Chi Square Test analysis was employed in this work to establish an empirical relationship between flooding and its deleterious outcomes such as destruction of property and the outbreak of diseases. To the best knowledge of the 
researchers based on widely reviewed literature on flooding in Nigeria, the chi square has not been employed as a methodological approach to test inferentially the impact of flood events in the country.

\section{Conclusion}

The National Emergency Management Agency (NEMA) is the department of the Nigerian government saddled with the constitutional responsibility of managing floods and other disasters in the country. Their interventions, however, are generally seen to be reactive, focusing on the distribution of relief materials after flood events. This approach to flood management is seen to be inadequate and top-down as they do not involve the affected communities in any decisions.

This study therefore employed participatory tools that involved these communities to determine the causes of flooding in these communities and the main areas of impact. The research concludes that flooding in the study area is mainly caused by the release of water from Ladgo Dam in Cameroon, and overflow of the Rivers Niger, Benue, and Meme, due to heavy rainfall. The research also concludes that the areas most affected by flood events include houses, farmlands, businesses and outbreak of diseases. The research also empirically determined that there is a relationship between flood events and destroyed property and infrastructure and the outbreak of diseases in the study area. Having established empirically that a relationship exists between destroyed infrastructure and diseases, and flooding, the research concludes that flooding is responsible for the destruction of basic amenities and the outbreak of some diseases in the affected communities. Therefore, participatory approaches are suitable for flood research and management because they ensure a bottom-up approach for robust flood management strategies.

\section{Conflicts of Interest}

The authors declare no conflicts of interest regarding the publication of this paper.

\section{References}

Adefisan, E. A., \& Egiku, J. (2018). Vulnerability Assessment of 2015 Flood in North Central Nigeria Using Integrated Approach of Hydrological Model and GIS. Global Scientific Journal, 6, 262-275.

Adefisan, E. A., Abdulkareem, S. B., \& Orimoloye, I. R. (2015). Application of Geospatial Technology in Identifying Areas Vulnerable to Flooding in Ibadan Metropolis. Journal of Environment and Earth Sciences, 5, 156-165.

Alabi, M. O. (2009). Urban Sprawl, Pattern, and Measurement in Lokoja, Nigeria. Theoretical and Empirical Researches in Urban Management, 4, 158-164.

Audu, S. M. (2009). A Reflection on the Nature of Inter-Group Relations in Lokoja, Nigeria. Journal of Sustainable Development in Africa, 11, 325-333.

Buba, F. N. (2016). Analysis of the Spatial Distribution of Lead Concentration in the Soil of Anka, Zamfara State, Nigeria. Journal of Environment Pollution and Human Health, 
4, 16-23.

Cinderby, S., \& Forrester, J. M. (2016). Co-Designing Possible Flooding Solutions: Participatory Mapping Methods to Identify Flood Management Options from a UK Borders Case Study. Journal for Geographic Information Science, 1, 149-156. https://doi.org/10.1553/giscience2016 01 s149

Demeritt, D., \& Nobert, S. (2014). Models of Best Practice in Flood Risk Communication and Management. Journal of Environmental Hazards, 13, 313-328. https://doi.org/10.1080/17477891.2014.924897

Development Studies Network (2013). Challenges for Participatory Development in Contemporary Development Practice. Development Bulletin No. 75.

FGN Federal Government of Nigeria (2013). Nigeria Post-Disaster Needs Assessment: 2012 Floods. A Report by the FGN with Technical Support from the World Bank, European Union, United Nations, and Other Partners.

Hu, X., Pant, R., Hall, J. W., Surminski, S., \& Huang, J. (2019). Multi-Scale Assessment of the Economic Impacts of Flooding: Evidence from Firm to Macro-Level Analysis in the Chinese Manufacturing Sector. Sustainability, 11, 1-18.

https://doi.org/10.3390/su11071933

Iyi, E. A., \& Ugwuanyi, B. C. (2014). Community Participation Approach to Flood Disaster Management: The Case of Enugu East Local Government Area of Enugu State, Nigeria. International Journal of Engineering Science Invention, 3, 4-13.

Kienberger, S., \& Steinbruch, S. (2005). PGIS and Disaster Risk Management: Assessing Vulnerability with PGIS Methods-Experiences from Buzi, Mozambique. Mapping for Change: International Conference on Participatory Spatial Information Management and Communication, Nairobi, 7-10 September 2005, 12 p.

Komolafe, A. A., Adegboyega, S. A., \& Akinluyi, F. O. (2015). A Review of Flood Risk Analysis in Nigeria. American Journal of Environmental Science, 11, 157-166. https://doi.org/10.3844/ajessp.2015.157.166

Kundu, A., \& Kundu, S. (2011). Flood Vulnerability Assessment Using PGIS Approach. Journal of Remote Sensing and GIS, 2, 8-22.

Maferetlhane, I. O. (2012). The Role of Indigenous Knowledge in Disaster Risk Reduction: A Critical Analysis. Unpublished Master's Thesis, Potchefstroom: North West University.

Maskrey, A. S., Mount J. N., Thorne, R. C., \& Dryden, I. L. (2016).Participatory Modeling for Stakeholder Involvement in the Development of Flood Risk Management Intervention Options. Environmental Modeling and Software, 82, 275-294.

https://doi.org/10.1016/j.envsoft.2016.04.027

Nharo, T. (2016). Modeling Floods in the Middle Zambezi Basin Using Remote Sensing and Hydrological Modeling Techniques. Master of Science Thesis, Harare: University of Zimbabwe.

Nkwunonwo, U. C., Malcolm, N., \& Brian, B. (2015). Flooding and Flood Risk Reduction in Nigeria: Cardinal Gaps. Journal of Geography and Natural Disasters, 5, 136.

Ojigi, M. L., Abdulkadir, F. I., \& Aderoju, M. O. (2013). Geospatial Mapping and Analysis of the 2012 Flood Disaster in Central Parts of Nigeria. 8th National GIS Symposium, Dammam, 15-17 April 2013, 14 p.

Okpala-Okaka, C., Ndukwu, R. I., \& Ebinne, E. S. (2013). Management of Flood Disaster Risks in Nigeria. Journal of Environmental Management and Safety, 4, 6-18.

Olorunfemi, F. B. (2011). Managing Flood Disasters under a Changing Climate: Lessons Learnt from Nigeria and South Africa. NISER Research Seminar Series, Ibadan, 3 May 
2011, 44 p.

Oluwaseun, O. O., Ibrahim, A. T., Ahmed, I. A., Samsudeen, O. A., \& Oladeinde, A. (2013). The Role of Earth Observation Satellites during the International Collaboration on the 2012 Nigeria Flood Disaster. 64th International Astronautical Congress, Beijing, 23-27 September 2013, 8 p.

Rabalao, R. T. (2010). The Social, Psychological, and Economic Impact of Flooding in Ga-Motla and Ga-Moeka Communities of Moretele District in North West Province, South Africa. Unpublished Master's Thesis, Bloemfontein: University of the Free State.

Santato, S., Bander, S., \& Schaller, M. (2013). The European Floods Directive and Opportunities Offered by Land Use Planning. CSC Report 12, Hamburg: Climate Service Center Germany.

Sayama, K., Fukami, K., Tanaka, S., \& Takeuchi, K. (2010). Rainfall-Runoff-Inundation Analysis for Flood Risk Assessment at the Regional Scale. International Symposium on a Robust and Resilient Society against Natural Hazards and Environmental Disasters, and the 3rd AUN/SEED-NET Regional Conference on Geo-Disaster Mitigation, Kyoto, August 24-26 2010, 11 p.

Tawari-Fufeyin, P., Paul, M., \& Godleads, A. O. (2015). Some Aspects of a Historic Flooding in Nigeria and Its Effects on Some Niger-Delta Communities. American Journal of Water Resources, 5, 7-16.

Ugoni, A., \& Walker, B. F. (1995). The Chi Square Test: An Introduction. COMSIG Review, 4, 1-5.

Umaru, J. U., \& Hafiz, S. S. (2019). Perceived Effects of Flood on Lives and Properties of the Residents of Lokoja, Kogi State, Nigeria. Discovery, 55, 441-452.

WMO World Meteorological Organization (2008). Urban Flood Risk Management-A Tool for Integrated Flood Management, Version 1.0. WMO/GWP Associated Programme on Flood Management, 2008: A Joint Initiative of the WMO and the Global Water Partnership. Technical Document No. 11. 